Article

\title{
Measuring Access and Egress Distance and Catchment Area of Multiple Feeding Modes for Metro Transferring Using Survey Data
}

\author{
Xia Li, Zhenyu Liu and Xinwei Ma *(D)
}

check for updates

Citation: Li, X.; Liu, Z.; Ma, X. Measuring Access and Egress Distance and Catchment Area of Multiple Feeding Modes for Metro Transferring Using Survey Data. Sustainability 2022, 14, 2841. https://doi.org/10.3390/su14052841

Academic Editor: Marilisa Botte

Received: 12 January 2022

Accepted: 23 February 2022

Published: 28 February 2022

Publisher's Note: MDPI stays neutral with regard to jurisdictional claims in published maps and institutional affiliations.

Copyright: (c) 2022 by the authors. Licensee MDPI, Basel, Switzerland. This article is an open access article distributed under the terms and conditions of the Creative Commons Attribution (CC BY) license (https:/ / creativecommons.org/licenses/by/ $4.0 /)$.

\author{
School of Civil and Transportation Engineering, Hebei University of Technology, Tianjin 300401, China; \\ diyilixia@126.com (X.L.); lzy13920014892@163.com (Z.L.) \\ * Correspondence: xinweima@hebut.edu.cn
}

\begin{abstract}
Multiple feeding modes, including walking, bus, private bike, docked bike-sharing, private electric bike (e-bike), car, and taxi, are applied for better accessibility in a metro-based trip. It is crucial to understand their access/egress distances and corresponding catchment areas of metro stations. This paper determines these two distances and accessible areas of stations for different feeding modes based on Nanjing Population Survey data and GIS data by using a network-based approach in Nanjing, China. Considering the distribution of access/egress distance, regression models are established for the exploration of the threshold of distance to delineate catchment areas. What is more, the spatio-temporal characteristics of multiple feeding modes are analyzed. The results indicate that the average feeding distance of walking is the shortest, but docked bike-sharing has the shortest average feeding time, about $8 \mathrm{~min}$. The average feeding time of private e-bikes is close to that of the private bike, but the feeding distance of private e-bikes is about 1.3 times as long as that of private bikes. Moreover, the origin of an over- $10 \mathrm{~km}$ transfer for accessing metro stations is usually far away from metro lines and the transferring station is mostly the terminal station. Generally, longer access distance means larger catchment area but the result is also influenced by the condition of street network. Moreover, catchment areas for the same feeding modes are different between urban and suburban areas.
\end{abstract}

Keywords: multiple feeding modes; metro; access distance; egress distance; catchment area

\section{Introduction}

Metro has become a promising means for alleviating congestion and mitigating environmental issues caused by automobiles [1]. In the last decade, rapid development of metro has been taking place at an unprecedented pace in China, impelled by economic progress and urbanization. Regarded as a sustainable travel mode, metro usually does not provide door-to-door service to travelers [2]. In general, a metro-based urban trip consists of at least three segments: an access segment from origins to metro stations, an in-metro segment, and an egress segment from stations to final destinations, involving transfers among multiple modes [3]. The integration of metro with other feeding modes usually enhances the accessibility of metro-based trips. Deep understanding of access/egress distances and catchment areas for different feeding modes is required for seamless connection between metro and other modes. At the same time, determining access distances, egress distances, and catchment areas of metro stations for multiple feeding modes helps formulate targeted strategies to improve walking-related facilities, adjust bus lines, locate docked bike-sharing points, and tap the potential of mode shift for car users $[4,5]$.

Therefore, in order to reflect the difference of multiple feeding modes, including walking, bus, private bike, docked bike-sharing, private e-bike, taxi, and car on access / egress distances and corresponding catchment areas for metro stations, this study mainly focuses on: 
- Calculating network-based access/egress distance and further determining the threshold to depict the service area by using the regression model for every mode;

- Comparing the transferring distances, corresponding spatio-temporal characteristics, and accessible areas for multiple feeding modes based on visualization.

The remainder of this paper is structured as follows: First, we review access/egress distances and catchment areas of metro stations for different feeding modes in Section 2. Next, study area, data source, and the methods employed are given in detail in Section 3. In Section 4, the comparison of access/egress distances and catchment areas of metro for these feeding modes are presented, and analysis of spatio-temporal characteristics is also covered. Finally, we draw a conclusion and make an outlook for this paper.

\section{Literature Review}

This section provides a comprehensive review of works related to this topic. To date, most research on the access/egress distances and catchment areas of metro stations can be categorized into three areas: integration of metro with walking, integration of metro with private bike, docked bike-sharing, and private e-bike, and integration of metro with bus, car, and taxi.

\subsection{Integration of Metro with Walking}

Walking is regarded as the most important mode to complete a trip based on metro [6]. However, the upper limits for passenger walking distance are different between metro stations across the entire system and different cities [7]. Walking distances ranging from $300 \mathrm{~m}$ to $800 \mathrm{~m}$ are considered as the commonly accepted walking distances to metro stations [8,9]. Kuby et al. assigned a fixed value of $800 \mathrm{~m}$ for walking access distance, which is the standard walking distance used to delimit catchment areas of metro station in most transit research [10,11]. A transit access survey including revealed and stated information, and Rastogi et al. reported that walking mode is dominant within an access distance of $1250 \mathrm{~m}$, with an average distance of $910 \mathrm{~m}$ for different categories of commuters in Mumbai, India [12]. Several studies concentrated on predicting walking access/egress distance by means of regression analysis. For instance, Wang et al. not only obtained $657 \mathrm{~m}$ and $1092 \mathrm{~m}$ as the mean and 85th percentile value of egress distance, respectively, in Minneapolis and St. Paul metropolitan area, but also adopted Poisson models to explore the effects of building environments on egress distance [3]. Another research carried out in Nanjing, China, estimated the mean walking distance for accessing different metro station contexts as $882 \mathrm{~m}$ for common stations, $682 \mathrm{~m}$ for transfer ones, $1291 \mathrm{~m}$ for terminal stations, $848 \mathrm{~m}$ for underground ones, and $1031 \mathrm{~m}$ for elevated metro stations [13].

\subsection{Integration of Metro with Private Bike, Bike-Sharing, and E-Bike}

A marriage between bike and metro presents new opportunities for sustainable transportation [14]. The integration of bike and metro transit helps overcome the demerits of metro, for example, to solve the last-mile issue [15]. In terms of the threshold distance of cycling to metro stations, Taylor et al. concluded a bike access distance of $2.4 \mathrm{~km}$ through a stated preference survey [16]. A more accurate assessment of bike access distance conducted in the Los Angeles and Atlanta regions illustrated that the average cycling distance for Atlanta is $1730 \mathrm{~m}$, which is significantly different from that of $4436 \mathrm{~m}$ in the Los Angeles area [17]. Lee et al. chose the 85th percentile value of the access distance as the bike access distances of $1.96 \mathrm{~km}$ for origin (home)-to-station trips and $2.13 \mathrm{~km}$ for station-to-work trips using regression and cumulative distribution models [18]. Notably, some studies focused on the incorporation of bike-sharing system and metro. Cheng et al. used the multinomial logit model to determine changes in metro service coverage after the launch of bike-sharing system and found that the coverage expands in Kaohsiung [19]. Research presented by Ma et al. estimated that $10 \%$ increase of Capital Bikeshare ridership will contribute to a 2.8\% increase in Metrorail ridership in Washington, D.C. [20]. In addition, private e-bikes have been recently deemed as an independent mode in daily travels rather than a feeder 
mode to metro. For one part, private e-bikes make it possible to substitute motorized modes when the distance is perceived to be too long for regular bikes [21]. For another part, unlike conventional bikes, private e-bikes requires fewer physical efforts for a higher speed to cover longer distance [22]. As for travel distance, Plazier et al. found that private e-bikes, which can provide a good alternative to the use of a car, covers an average of $14.1 \mathrm{~km}$ in commuting [23]. Talamini and Ferreira found that e-bike taxicab service can enlarge the catchment area of the transit system and thus reduce the social exclusion of rural enclaves in the city [24]. Using dockless bikeshare trajectory data, Lin et al. found that the average size of bike-sharing catchment increases from $4.34 \mathrm{~km}^{2}$ (inner zone) to $7.26 \mathrm{~km}^{2}$ (suburban zone) and the sizes of the bike-sharing catchment were positively associated with good metro service and frequent morning trips [25]. Recently, Guo et al. used $100 \mathrm{~m}$ buffer for the measurement of the integration of dockless bike-sharing and metro access/egress [26]. They found that the majority of access/egress feeding trips had a distance range of 500-2000 m. In addition, they suggested that the shared bikes are better to put with a priority at the area immediately adjacent to metro stations $(<100 \mathrm{~m})$ for egress and the area within 800-1500 $\mathrm{m}$ for access.

\subsection{Integration of Metro with Bus, Car, and Taxi}

Other modes like bus, car, and taxi, which contribute to a portion of access/egress trips of metro stations, are also important, although they are less attended by researchers and planners [27]. Overall, compared with car and taxi, the metro-bus travel pattern gets more concerns due to the largely improved accessibility for a medium, even a long-distance, trip [28]. According to the research in Hidaka City, Japan, bus is the dominant mode for reaching the metro station for commuters above 49 years old. Moreover, it observed that residential areas of public bus passengers are quite dispersed [29]. What is more, Yang et al. found that taking a bus for access or egress trips has longer commute times than other modes [30]. The role that cars and taxis play in transportation for metro is not only a competition but also a complement. Ralph Buehler reported that public transportation is more competitive than cars in urbanized areas and the rush hour commute [31]. It is also important to understand the P-and- $\mathrm{R}$ (parking at the transit station and riding transit) mode aims to attract suburban drivers towards transit, particularly in regions with extreme congestion or expensive parking [5]. For taxis, transit-extending taxi trips in New York, as observed by Wang et al., have a significantly shorter average trip length [32]. Li et al. noted that in Wuxi, China, taxis largely cover trips from areas that have no access to the subway [33]. Recently, a few studies utilized taxi's trajectory data to explore its relationship with metro. They categorized taxi trips into three types, namely, metro-competing, metroextending, and metro-complementing [33,34]. Specifically, metro-extending taxi trips are defined as taxi trips that connect to/from metro stations. Metro-extending taxi trips can be identified based on the following rules: (1) only one taxi trip end (either origin or destination) has a metro station within $300 \mathrm{~m} \mathrm{[33],} \mathrm{and} \mathrm{the} \mathrm{other} \mathrm{end} \mathrm{of} \mathrm{the} \mathrm{trip} \mathrm{does} \mathrm{not}$ have any metro station within $2 \mathrm{~km} \mathrm{[34];} \mathrm{(2)} \mathrm{the} \mathrm{taxi} \mathrm{trip} \mathrm{must} \mathrm{happen} \mathrm{during} \mathrm{the} \mathrm{metro}$ operation time.

Although previous studies have proposed numerous methods to estimate the access/egress distance and catchment area for metro transferring, there are still some research gaps. First, most previous research focused on walking, private bike, bike-sharing, and private e-bike as feeding modes, with few concerns about bus, car, and taxi. Second, access distance is mostly regarded as a measure for catchment area of metro stations to some extent, however few studies calculated the catchment area additionally for every feeding mode for metro transferring. Third, although some studies compared these feeding modes, little did they examine their access and egress distances and catchment areas while simultaneously exploring the personal and travel characteristics of metro passengers' choice of transfer modes. To combine the advantages of metro and other feeding modes, a better understanding of the access/egress distances and corresponding catchment areas is necessary. 
Therefore, this paper attempts to fill the research gaps by figuring out the characteristics of multiple feeding modes on access/egress distances and catchment areas in Nanjing, China.

\section{Methodology}

\subsection{Study Area}

Nanjing, as the capital of Jiangsu Province, China, covers an area of $6587 \mathrm{~km}^{2}$ with a total population of 8.33 million [35]. In the last two decades, it has, along with other Chinese metropolises, witnessed sustained and rapid urbanization, economic growth, and motorization. Nanjing has a huge and complex urban transportation system, where multiple modes of transport interact with each other. They mainly include metro, bus, private bike, docked bike-sharing, private e-bike, walking, car, and taxi. To adapt to increasing urban growth and meet travel demand, the Nanjing Metro has opened 11 operating lines as of December 2021, a total of 191 stations [36]. These lines, coupled with over 700 bus lines, constitute a powerful public traffic network [37]. Besides, robust use of private e-bikes and conventional bikes thanks to the city's plain topography also helps meet the travel demand to a great extent.

Figure 1 displays the study area of this paper, the light blue region is the main districts of Nanjing, and the downtown refers to the area inside the inner ring of Nanjing. Since the Nanjing Metro opened 6 metro lines when the data was collected in 2015, the current research will determine the access/egress distances and catchment areas of metro stations along these lines overall.

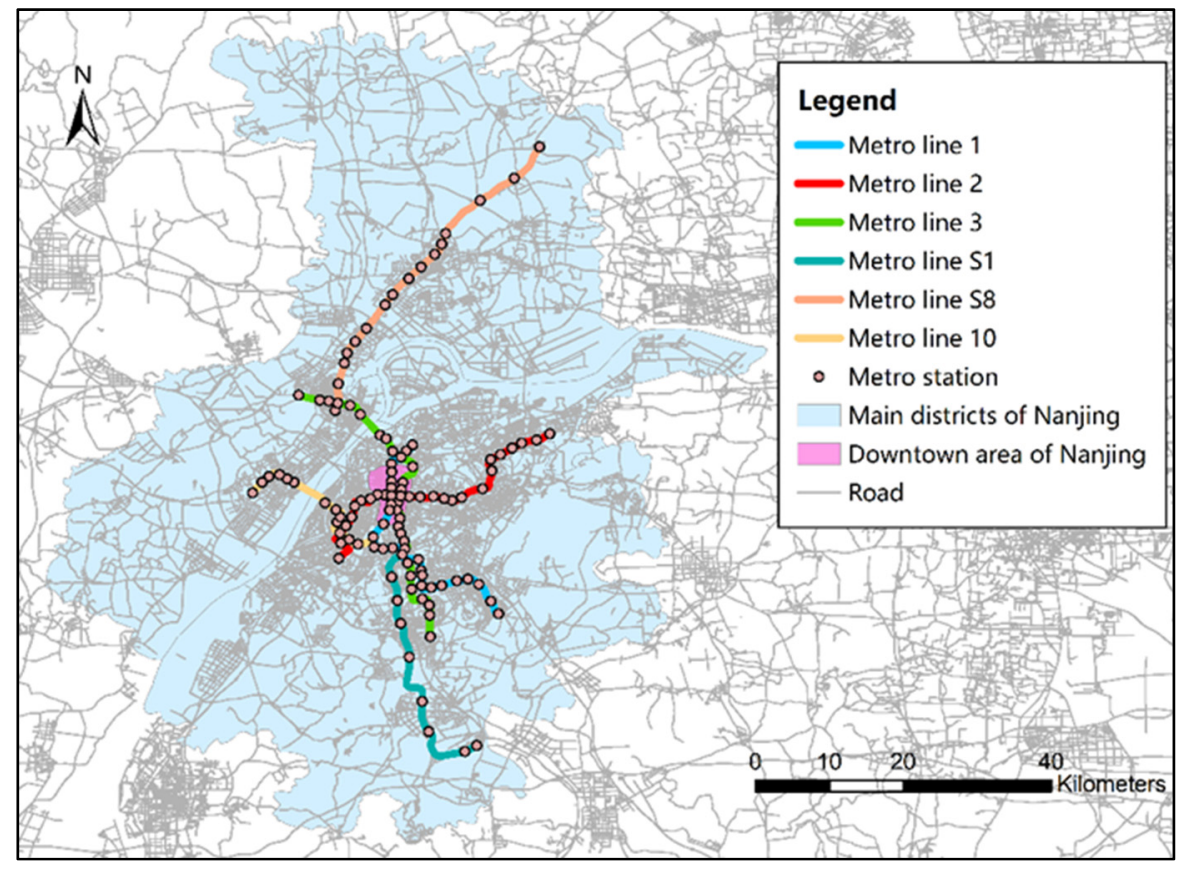

Figure 1. Illustration of study area.

\subsection{Data Collection}

In this paper, the required data mainly includes Nanjing Population Survey data and GIS data of Nanjing, provided by Jiangsu Institute of Urban Planning and Design and the Jiangsu Institute of Urban Transport Planning. The survey was conducted from Tuesday to Thursday for two weeks (16-18 June, 23-25 June) in 2015, and the data files comprise personal information, household information, and travel information, a total of 162,190 trips. To measure access/egress distances and catchment areas of metro stations for multiple feeding modes, we picked the travel data with origin-metro station-destination travel pattern and corresponding personal data, a total of 2891 trips. The data in detail contains the following information: 
- Trip data, including the longitude and latitude of origin and destination; the name of aligned metro station; feeding modes and corresponding transferring time consumption. - Personal data, including gender; age; education; income, etc.

It should be pointed out that the initial travel data, which is used for the analysis of transfer mode share, includes 2891 access segments, while only 1706 egress segments are due to the lack of feeding modes documented in the egress phase. To measure the access or egress distance for different feeding modes, some ambiguous data that has no exact names of transferred metro stations is excluded and the remaining data contains 1468 trips of access and 1125 trips of egress.

In addition, the GIS data obtained includes geographic information of street network, 6 metro lines, and all the positions of metro stations. A later section uses aforementioned data for the analysis of access/egress distance and catchment area.

\subsection{Access/Egress Distance Calculation}

Both Euclidean distance and network-based distance can be obtained by ArcGIS using geocoded data of origins and destinations. As the Euclidean distance does not cover detours, it is shorter than the distance people travel to access/egress the metro stations in actual street network. Therefore, a network-based approach is adopted in this paper by way of Network Analyst tool in ArcGIS. As Figure 2 shows, this method, relying deeply on the integrity of street network, is expected to find a path with the shortest distance between an origin/destination and a metro station. Assuming that travelers tend to take the shortest path on street network, this path found by the method is regarded as the actual path the traveler takes.

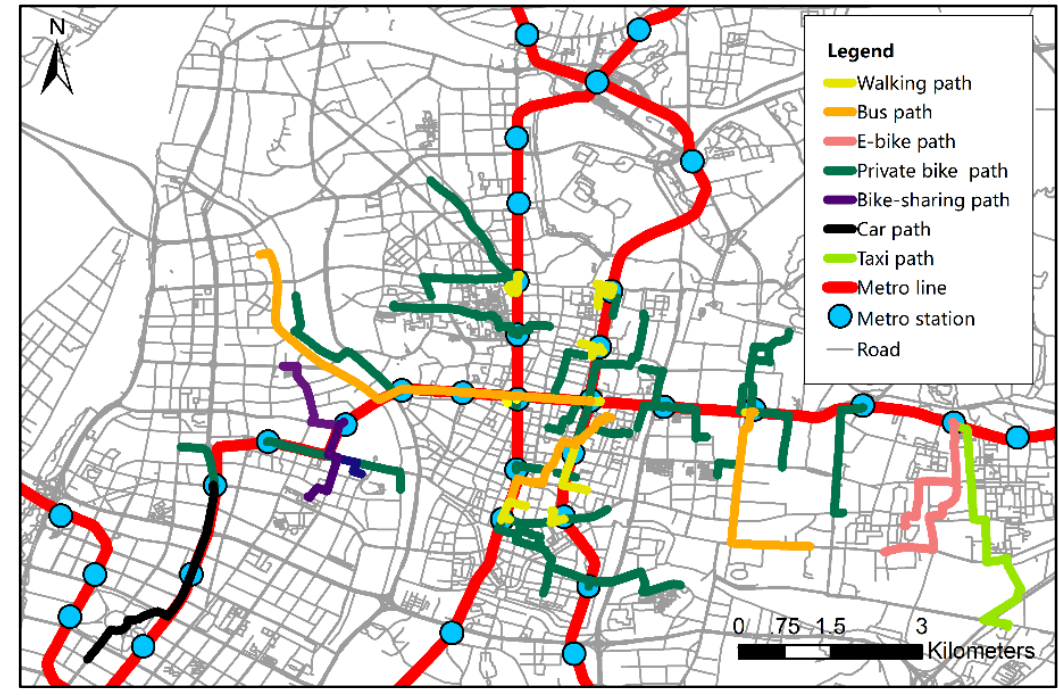

Figure 2. Paths of different feeding modes generated on the street network.

After the calculation of access and egress distance of every trip, the threshold of access/egress distance can be determined for different feeding modes. Generally, the threshold of access/egress distance, which can cover most metro passengers' trips, is deemed as the 85th percentile of the cumulative distribution of access/egress distance [1,3]. In other words, most travelers are willing to access or egress stations by a certain feeding mode within the threshold.

As for the method to estimate the threshold, an arrival cumulative percent graph was initially presented by Hino et al. to estimate the spatial extent that people can reach to accessible adjacent station area [38]. Based on this approach, Lee et al. revealed a clear correlation between the cumulative arrival distribution of metro passengers and the distance 
from the station and obtained the 85th percentile value by using Quadratic regression and Cubic regression later [18], which are respectively expressed as:

$$
\begin{gathered}
y=\alpha_{0}+\alpha_{1} x_{1}+\alpha_{2} x_{1}^{2} \\
y=\beta_{0}+\beta_{1} x_{1}+\beta_{2} x_{1}^{2}+\beta_{3} x_{1}^{3}
\end{gathered}
$$

where $x_{1}$ is access distance, $y$ is cumulative percent $(\%)$, while $\alpha_{i}(i=0,1,2)$ and $\beta_{j}(j=$ $0,1,2,3)$ are regression coefficients for Quadratic and Cubic model, respectively.

In this paper, we adopt Lee's method to establish Quadratic model and Cubic model for multiple feeding modes in view of the non-linear distribution of access/egress distance respectively [18], and then choose the better explanatory model to determine the 85th percentile value of the both distances, meaning that the dependent variable y will be fixed as $85 \%$.

\subsection{Catchment Area Delineation}

By and large, two methods are widely applied for shaping catchment areas of metro stations $[4,13]$. One, the circular buffer method, does not take into account the conditions of roads and the other comes into being based on the street network. The former, which is easier and labor-saving for us to get the results, covers areas that are not accessible for multiple feeding modes, and thus may overestimate service areas compared with the network-based method. Given the objective of this study, it is more reasonable to adopt the second approach to obtain more precise data of catchment areas.

Catchment areas of metro stations for multiple feeding modes are identified as the areas that can be accessed by these modes, whose spatial boundaries are determined by the corresponding distance threshold of every feeding mode. In general, the 85th percentile of the access distance is widely accepted for catchment area delineation in relevant studies [1,17], which is also employed in this paper. This value is estimated by the regression models mentioned in the last section. Once the threshold is ascertained, the catchment area based on street network can also be generated by ArcGIS. Moreover, the corresponding area of these service areas can be then calculated. The process of catchment area delineation is similar to the access/egress distance calculation on the network: first, the target metro station is added to the network; then the service area boundary on the network is found along every possible path on the network from a metro station. Additionally, a boundary vertex is marked on the network taking the access distance as the cut-off length; when all of the roads starting from the station experience a process like this, an out-of-shape catchment area of the station is finally generated [4].

\section{Results}

\subsection{Analysis of Personal and Travel Characteristics}

Demonstrated in Figure 3, the analysis for survey data reveals several distinctive characteristics of metro passengers' choice of transfer mode. Walking, as valid observations show, is dominant in both access and egress stages, accounting for $71.22 \%$ and $69.6 \%$, respectively. This conclusion is consistent with the previous findings [4,39]. Following it is the bus, which takes up $11.73 \%$ of access trips to metro and $13 \%$ of metro egress trips. This result coincides with the finding from [40], in which the second most used access mode for metro is bus. In this research, a distinction is made between private bike, docked bike-sharing, and private e-bike. As Figure 3 shows, private bikes have a modest share at $3.32 \%$ and $3.1 \%$ for accessing and egressing stations. In Nanjing, private bikes are forbidden to bring on the metro, so one private bike can only be chosen as the feeding mode for one-way, accessing, or egressing. Besides, the weather during the survey implementation was not very good, more than half time it was rainy, which had a certain negative impact on the use of bicycles [40]. Docked bike-sharing, however, is not as popular as expected, with the two shares at $1.56 \%$ for access and $2.2 \%$ for egress, respectively. This may be because docked bike-sharing was just in its infancy when the survey was conducted in 2015. Specifically, it is visible through a larger docked bike-sharing use at egress than 
access. This situation may be caused by the convenience of bike-sharing use for egressing metro. In Nanjing, docked bike-sharing stations are allocated at most metro stations within $300 \mathrm{~m}$ [41]. Passengers can easily rent shared bikes after exiting the metro stations. Private e-bikes, which represent one of the fastest growing segments of the transport market, for their part, are getting rising concerns from the public [42]. They enjoy a higher share than docked bike-sharing of $2.66 \%$ in accessing metro, while the share of the two modes is nearly equal to each other in the egress phase. At the same time, perhaps considering travel cost, only a small percentage of people access/egress metro stations by car or taxi. Other choices, mainly including motorcycles, e-bikes, taxicabs, and official cars, take up $6.50 \%$ of access trips to metro and $7.7 \%$ of metro egress trips.

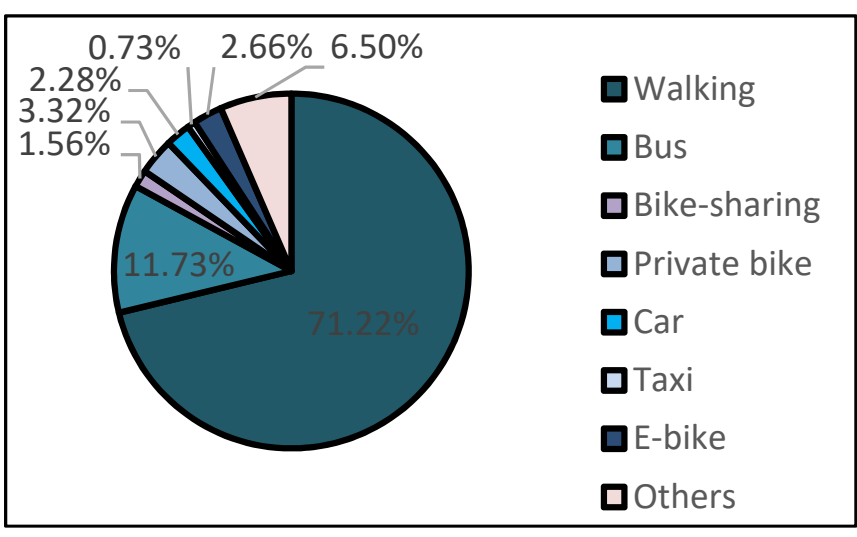

(a)

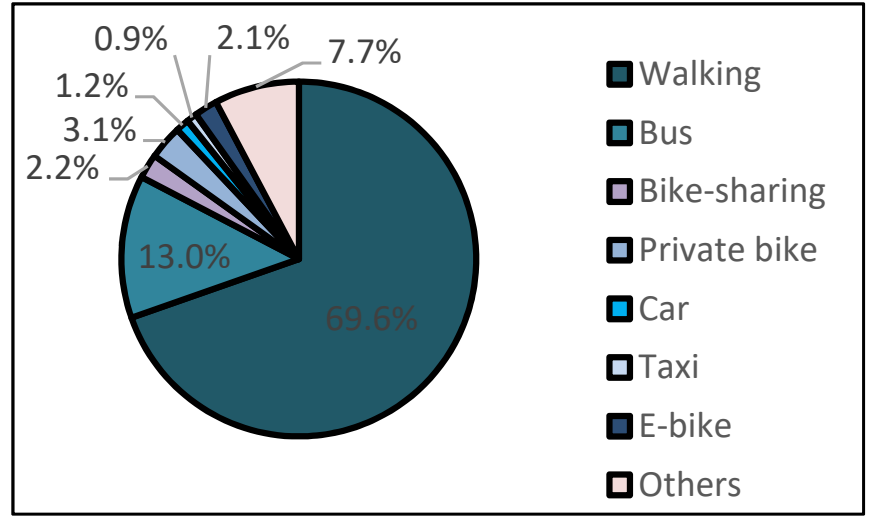

(b)

Figure 3. Distribution of transfer mode shares of accessing (a) and egressing (b) station.

The distributions of transfer mode choice in both access and egress phases by gender group and age group are depicted in Figure 4. In terms of different gender, the distribution of transfer mode choice is basically consistent with the previous distribution of transfer mode share. Due to the different sample sizes of access trips and egress trips, it is unreasonable to compare the number of trips of the same gender in these two phases directly. Furthermore, the sample size of women was larger than that of men. Although there is no remarkable difference between males and females within the same feeding mode, compared with women, men prefer to use private bikes to access stations, private e-bikes to egress stations, and to use cars in both feeding phases. According to (b) and (c), the distribution of transfer mode choice by seven age groups for accessing station is similar to that for egressing station. Teenagers under 15 years old are more likely to choose walking to access and egress with metro. This is reasonable because they may have no personal bikes and e-bikes. Besides walking, they are also likely to take their parents' car to access to the metro stations due to parents' habit of escorting their children to school in the morning [43]. However, they choose buses instead of parents' cars to egress to the metro stations due to parents not having time to escort them. People between 26 and 35 years old may prefer riding a shared bike to metro stations or to destinations from stations than other age groups, while it seems that people who are at 35-45 would like to take their own bikes or private e-bikes as feeding modes comparing to other age groups. Old passengers mainly choose walking to access and egress with metro, followed by bus and private bikes. This finding is reasonable because old travelers prefer healthy and economical travel modes. 


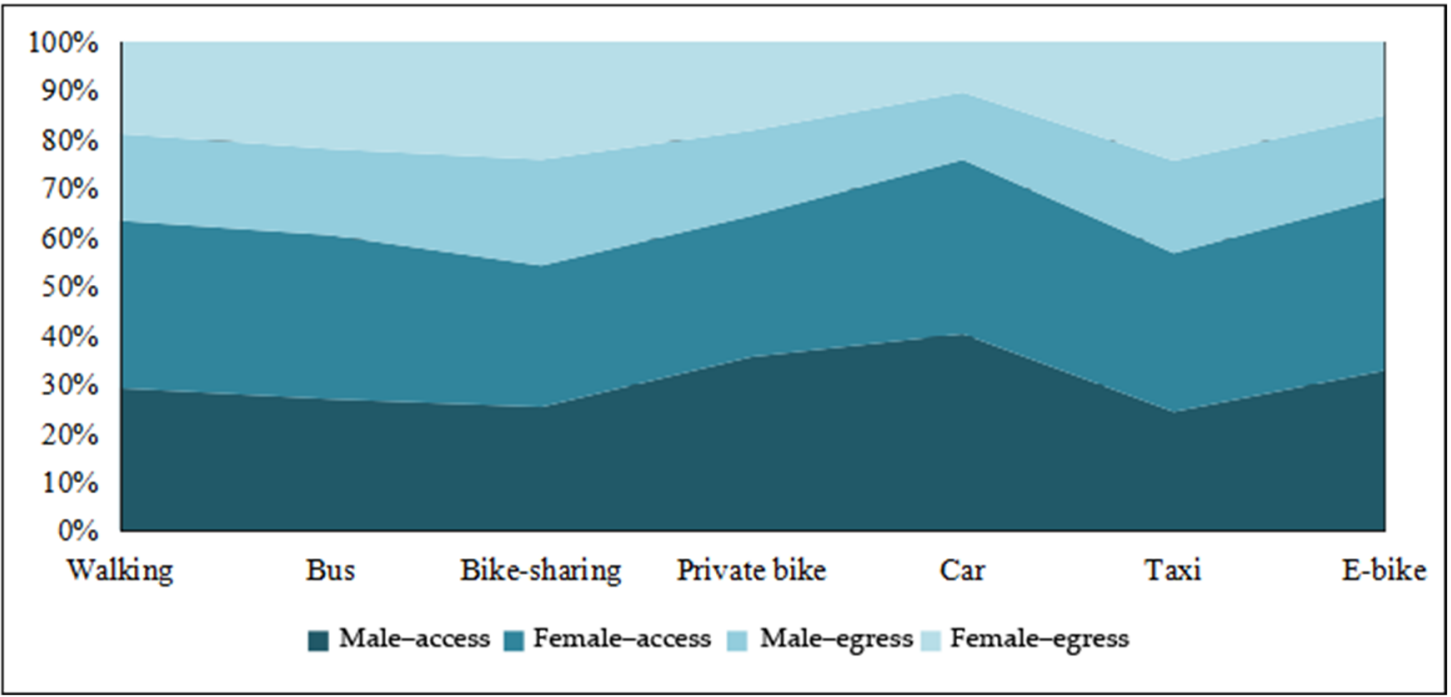

(a) Trip distribution of transfer mode choice of access and egress by gender.

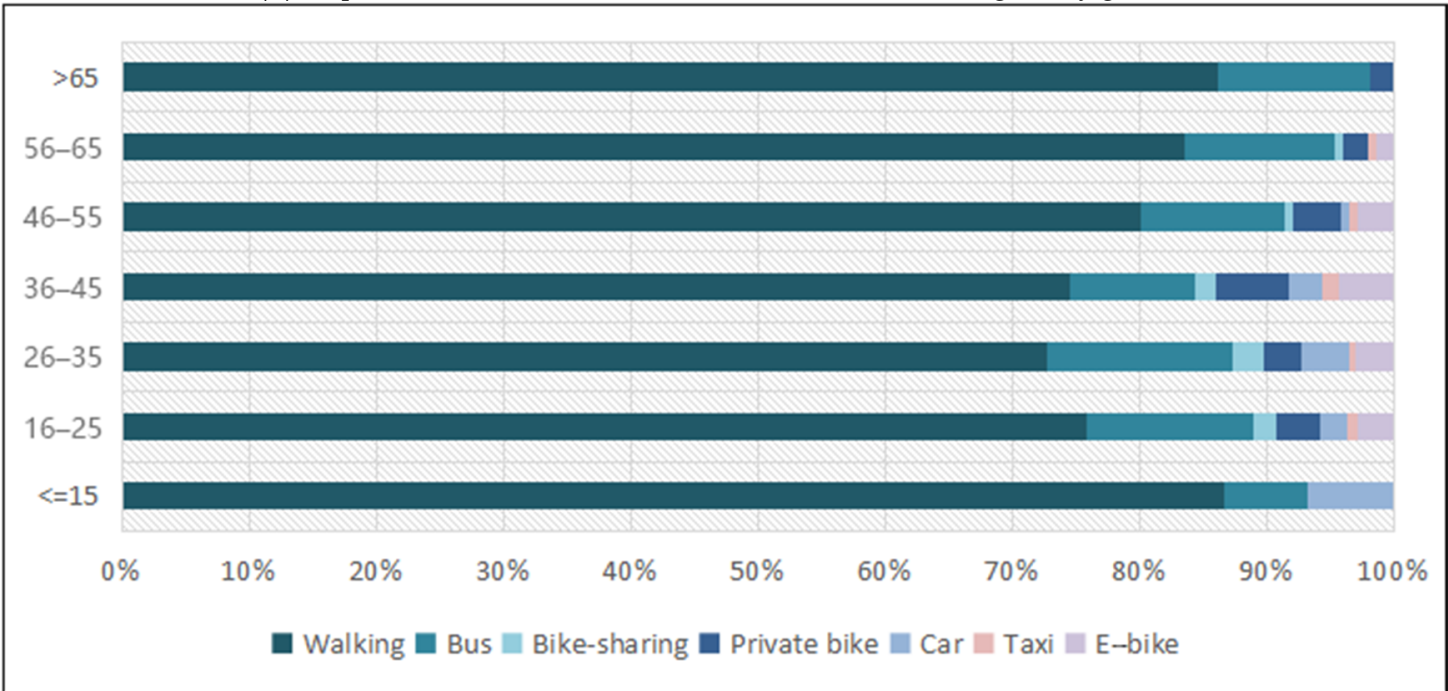

(b) Trip distribution of transfer mode choice of access by age groups.

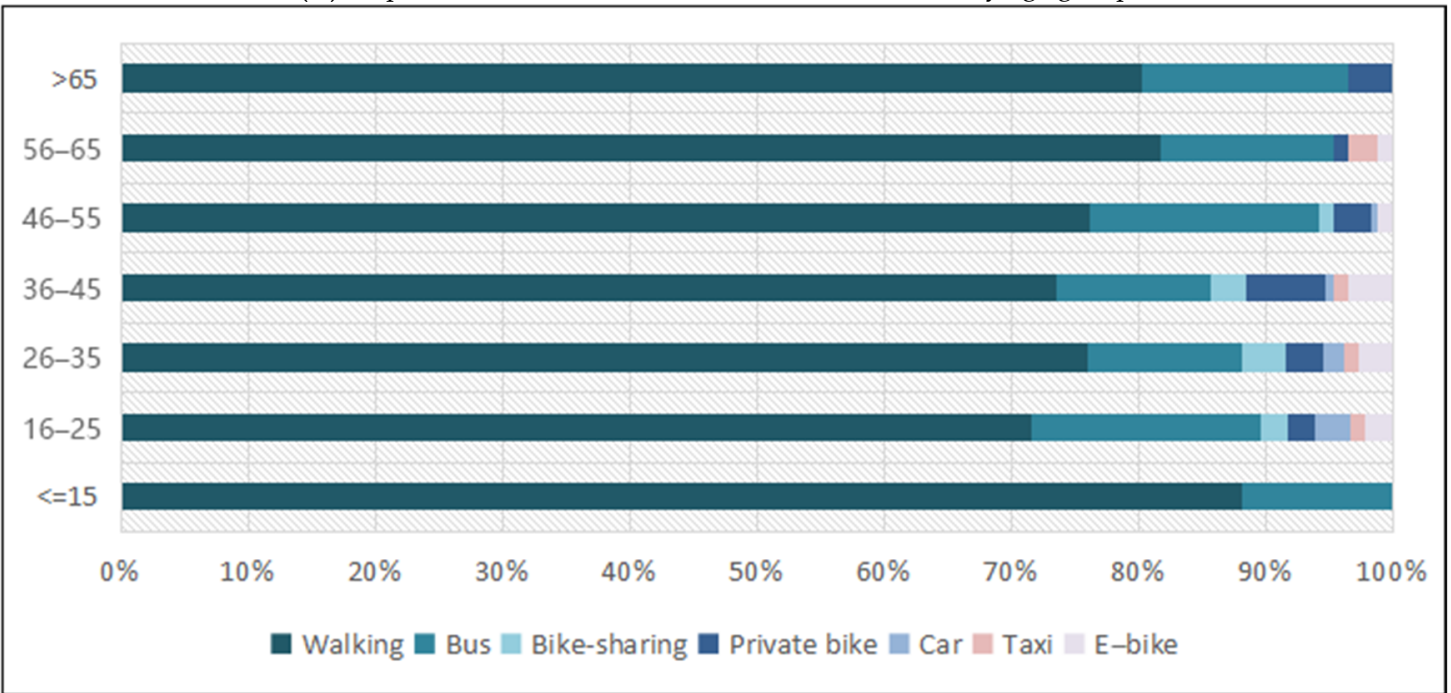

(c) Trip distribution of transfer mode choice of egress by age groups.

Figure 4. Distribution of mode choice of access and egress by gender group (a), age group (b,c). 


\subsection{Access/Egress Distance of Metro Station}

The access distances and egress distances of metro stations on the basis of street network for each trip are calculated by GIS method. As mentioned, quadratic regression and cubic regression between the access distance $x_{1}$ /egress distance $x_{2}$ and cumulative percent $y(\%)$ are developed for multiple feeding modes in access and egress phases, and a better explanatory model is presented in Table 1 . It can be concluded that the models displayed in the table obtain preferable performance with $\mathrm{R}^{2}$ greater than 0.95 and significance lower than 0.01 , except for taxis in both phases. Despite a relatively small sample size, the significance of two distance models of taxi is still below 0.05 , which is satisfactory as well. The purpose of establishing regression models is to find out the 85th percentile value of the cumulative distribution of the access/egress distance. By fixing the dependent variable $y$ as $85(\%)$, the 85 th percentile value of different feeding modes is calculated and the results are shown in Table 2.

Table 1. Regression models of access and egress distance.

\begin{tabular}{|c|c|c|c|c|}
\hline & Feeding Mode & Regression Model & $\mathbf{R}^{2}$ & Sig. \\
\hline \multirow{7}{*}{ Access } & Walking & $y=-7.212+0.068 x_{1}+2.630 \times 10^{5} x_{1}^{2}-1.747 \times 10^{8} x_{1}^{3}$ & 0.994 & 0.000 \\
\hline & Docked bike-sharing & $y=117.062-0.257 x_{1}-0.0002 x_{1}^{2}-3.272 \times 10^{8} x_{1}^{3}$ & 0.986 & 0.000 \\
\hline & Private bike & $y=3.026-0.018 x_{1}+4.008 \times 10^{5} x_{1}{ }^{2}-7.847 \times 10^{9} x_{1}{ }^{3}$ & 0.989 & 0.000 \\
\hline & Private e-bike & $y=-19.468+0.026 x_{1}+4.293 \times 10^{6} x_{1}^{2}-9.877 \times 10^{10} x_{1}^{3}$ & 0.990 & 0.000 \\
\hline & Taxi & $y=-145.618+0.204 x_{1}-7.354 \times 10^{5} x_{1}^{2}+8.564 \times 10^{9} x_{1}^{3}$ & 0.970 & 0.015 \\
\hline & Bus & $y=-19.005+0.024 x_{1}-1.735 \times 10^{6} x_{1}^{2}+4.413 \times 10^{11} x_{1}^{3}$ & 0.987 & 0.000 \\
\hline & Car & $y=-12.547+0.022 x_{1}-1.654 \times 10^{6} x_{1}^{2}+4.671 \times 10^{11} x_{1}^{3}$ & 0.985 & 0.000 \\
\hline \multirow{7}{*}{ Egress } & Walking & $y=-9.005+0.090 x_{2}-1.793 \times 10^{6} x_{2}{ }^{2}-8.520 \times 10^{9} x_{2}{ }^{3}$ & 0.974 & 0.000 \\
\hline & Docked bike-sharing & $y=-53.019+0.083 x_{2}-1.619 \times 10^{5} x_{2}{ }^{2}+1.311 \times 10^{9} x_{2}{ }^{3}$ & 0.992 & 0.000 \\
\hline & Private bike & $y=-14.261+0.032 x_{2}+9.282 \times 10^{6} x_{2}^{2}-2.471 \times 10^{9} x_{2}{ }^{3}$ & 0.988 & 0.000 \\
\hline & Private e-bike & $y=-30.122+0.061 x_{2}-1.072 \times 10^{5} x_{2}{ }^{2}+7.190 \times 10^{10} x_{2}{ }^{3}$ & 0.992 & 0.000 \\
\hline & Taxi & $y=-15.409+0.029 x_{2}-1.763 \times 10^{6} x_{2}{ }^{2}$ & 0.920 & 0.021 \\
\hline & Bus & $y=-19.774+0.022 x_{2}-1.611 \times 10^{6} x_{2}{ }^{2}+4.074 \times 10^{11} x_{2}{ }^{3}$ & 0.985 & 0.000 \\
\hline & Car & $y=3.177-0.002 x_{2}+1.826 \times 10^{6} x_{2}{ }^{2}-8.580 \times 10^{11} x_{2}{ }^{3}$ & 0.960 & 0.000 \\
\hline
\end{tabular}

Table 2. Results of access and egress distance.

\begin{tabular}{|c|c|c|c|c|c|c|}
\hline \multirow{2}{*}{ Feeding Mode } & \multicolumn{2}{|c|}{ Access (m) } & \multirow{2}{*}{$\mathbf{N}$} & \multicolumn{2}{|c|}{ Egress (m) } & \multirow{2}{*}{$\mathbf{N}$} \\
\hline & Mean & 85th Percentile & & Mean & 85th Percentile & \\
\hline Walking & 784 & 1255 & 955 & 777 & 1271 & 775 \\
\hline Docked bike-sharing & 1809 & 2418 & 40 & 1993 & 2969 & 36 \\
\hline Private bike & 1741 & 2469 & 63 & 1761 & 2470 & 39 \\
\hline Private e-bike & 2423 & 3673 & 49 & 2220 & 3679 & 28 \\
\hline Taxi & 3590 & 4785 & 21 & 4467 & 4955 & 16 \\
\hline Bus & 4906 & 8097 & 206 & 5739 & 10506 & 157 \\
\hline Car & 4910 & 8854 & 52 & 7844 & 10605 & 20 \\
\hline
\end{tabular}

The average access and egress distances of walking, docked bike-sharing, private bikes, and private e-bikes are almost identical. Relatively speaking, the egress distances of taxi, bus, and car are longer than that of their access distance due to different travel characteristics of individuals and different sample size in trip collection and distribution. It is not surprising that walking has the shortest distance among all feeding modes, with the 
mean value at $784 \mathrm{~m}$ and $777 \mathrm{~m}$ for access and egress, respectively, which is also in line with the previous studies' determination that $800 \mathrm{~m}$ is the standard walking distance to metro station [11]. Following walking is cycling. The characteristics of docked bike-sharing and private bike somewhat differs. From Table 2, it can be found that the average access and egress distance of docked bike-sharing are both slightly larger than that of the private bike due to the docking bike-sharing stations. As for private e-bikes, the advantages in speed and physical exertion make the feeding distance longer than that of conventional bikes. Besides, perhaps due to the fares and convenience concerns, the mean feeding distance of taxi is not as long as that of car and the distribution of distance for taxi is more concentrated. The average access and egress distances are $3590 \mathrm{~m}$ and $4467 \mathrm{~m}$, respectively. At the same time, car and bus share the similar mean distance in access phase. As for egressing metro station, the mean distance of bus is shorter than car but its 85th percentile of egress distance nearly equals to that of car. This indicates that car users may shift to bus if better bus services are provided while accessing or egressing metro stations. The average detour index, which represents the extent of detouring, is calculated by dividing total network distance by total Euclidean distance [44]. For walking, the value is 1.32 for both access and egress phases, which is between the recommended value of 1.2 and the maximum value of 1.4 proposed by Vuchic et al. [45]. The average detour indexes of other feeding modes are also within this range, indicating to some extent a relatively good street network of Nanjing.

\subsection{Analysis of Spatio-Temporal Characteristic for Multiple Feeding Modes}

In order to further understand the characteristics of multiple feeding modes, the total travel time is analyzed as shown in Figure 5. The total travel time consists of three parts, including the time from origin to metro station, the time on the metro (including transferring time and waiting time), and the time from the metro station to destination. A total of 1672 trips with complete travel time records are extracted and the mean value of time consumption of different feeding modes for the three parts are calculated as well. In general, the average total travel time for taking bus as a feeder mode is the longest, and there is a similar conclusion in Yang's research [30]. For the same mode, the average time for accessing stations is similar to that for egressing stations, which is about 9 min for walking, about $8 \mathrm{~min}$ for docked bike-sharing, and about $11 \mathrm{~min}$ for both private bike and private e-bike, while the feeding distance of private e-bike is about 1.3 times as long as that of private bike. As for taxi and car, the mean value is about $14 \mathrm{~min}$ and $16 \mathrm{~min}$, respectively. Besides, bus has the longest average feeding time, which is about $20 \mathrm{~min}$. At the same time, accessing or egressing stations by bus and car consumes more time in the second phase, which is partly due to the inconvenience of transfers. For bus, it is possible that the schedules are not effectively coordinated between bus and metro lines. Regarding car, the parking facilities may not be well provided around metro stations. Moreover, in terms of total travel time, most cases are less than one hour except when taking car and bus as feeding modes. It is notable that bus requires more access and egress time, though the average feeding distance is shorter comparing with car due to the multiple bus stops and relatively slower speed [46], which implies that the efficiency of this kind of long-distance travel needs to be improved. 


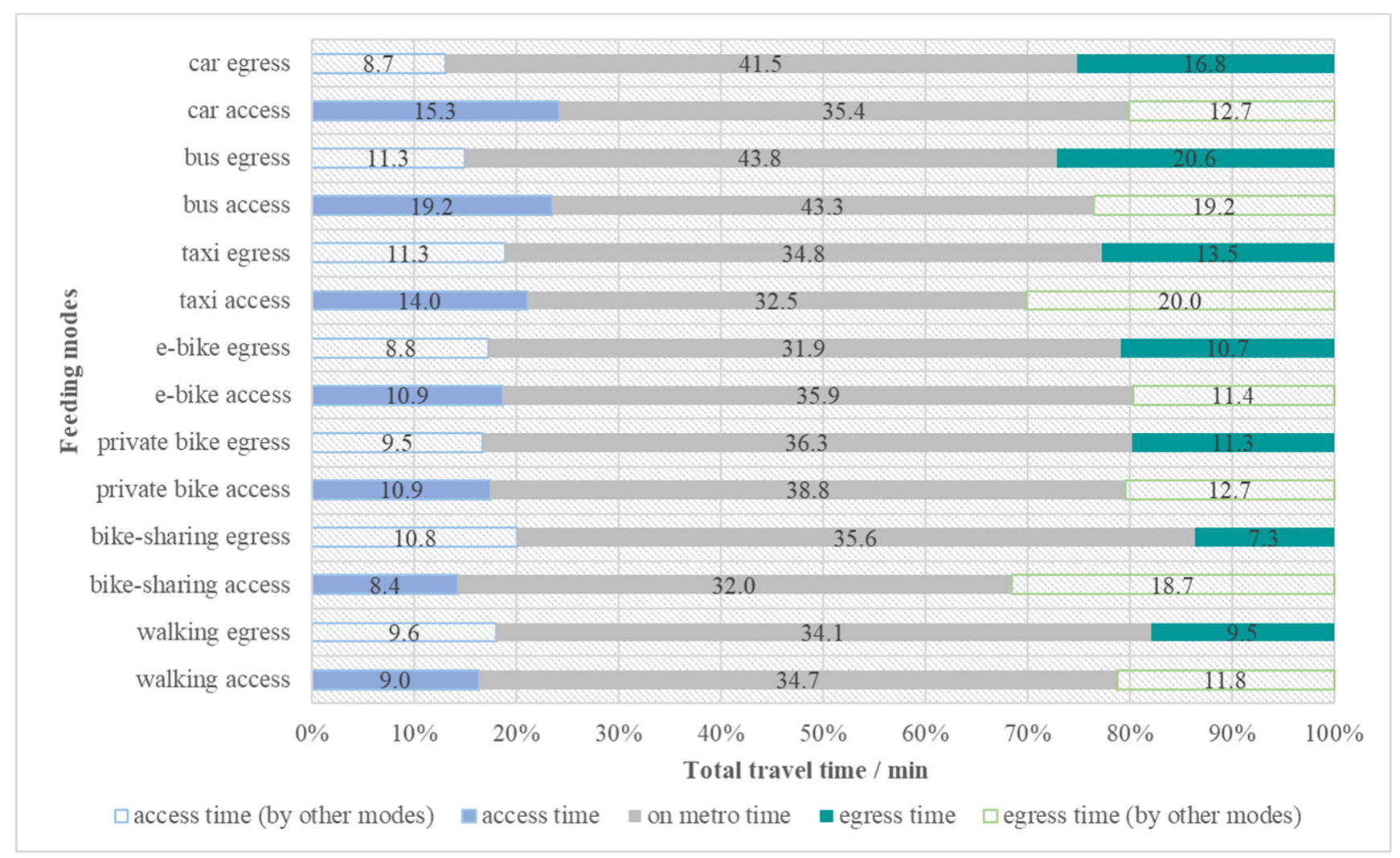

Figure 5. Total travel time for multiple feeding modes.

As shown in Figure 6, every $1 \mathrm{~km}$ is considered as a grade, then different categories of access trips are divided according to access distance. Different sizes of circles indicate the origin of access trips with different network-based distances. Similarly, there is some kind of characteristic for egress phase, but further discussion is not given due to the limitation of the length of this paper. The choice of accessing mode is largely influenced by the accessibility of multiple feeding modes around the origin, and the short access trips occur mostly in places around metro stations where the street network is denser, using walking, docked bike-sharing, private bike, or private e-bike. A longer distance access is generally achieved by car and bus, and the origin with access distance greater than $10 \mathrm{~km}$ is usually far from the metro lines and the transferring station is mostly the terminal station of the metro. It should be noted that some access trips with distances superior to $10 \mathrm{~km}$ start in the vicinity of metro stations, and this situation can be explained by way of the corresponding integrated metro stations not being the nearest ones. In light of the location of the origin of long-distance access, two categories can be roughly divided-one is far away from metro lines, but the surrounding street network conditions are relatively good, and the other is not only far away from metro lines but also located in an area with lower street network density. With the former, the focus is mainly on the improvement of bus service, such as providing real-time information of bus line and adjacent metro station. Concerning the second category, more attention should be paid to whether the origin of access trips falls within the range of bus stops. If there is no guarantee that a bus service can fully meet the demand of accessing stations, then the corresponding transfer metro station should provide convenient transfer conditions for car users. A previous study has shown that lack of parking facilities around metro stations is the primary cause of the inconvenience of car transfer [47]. 


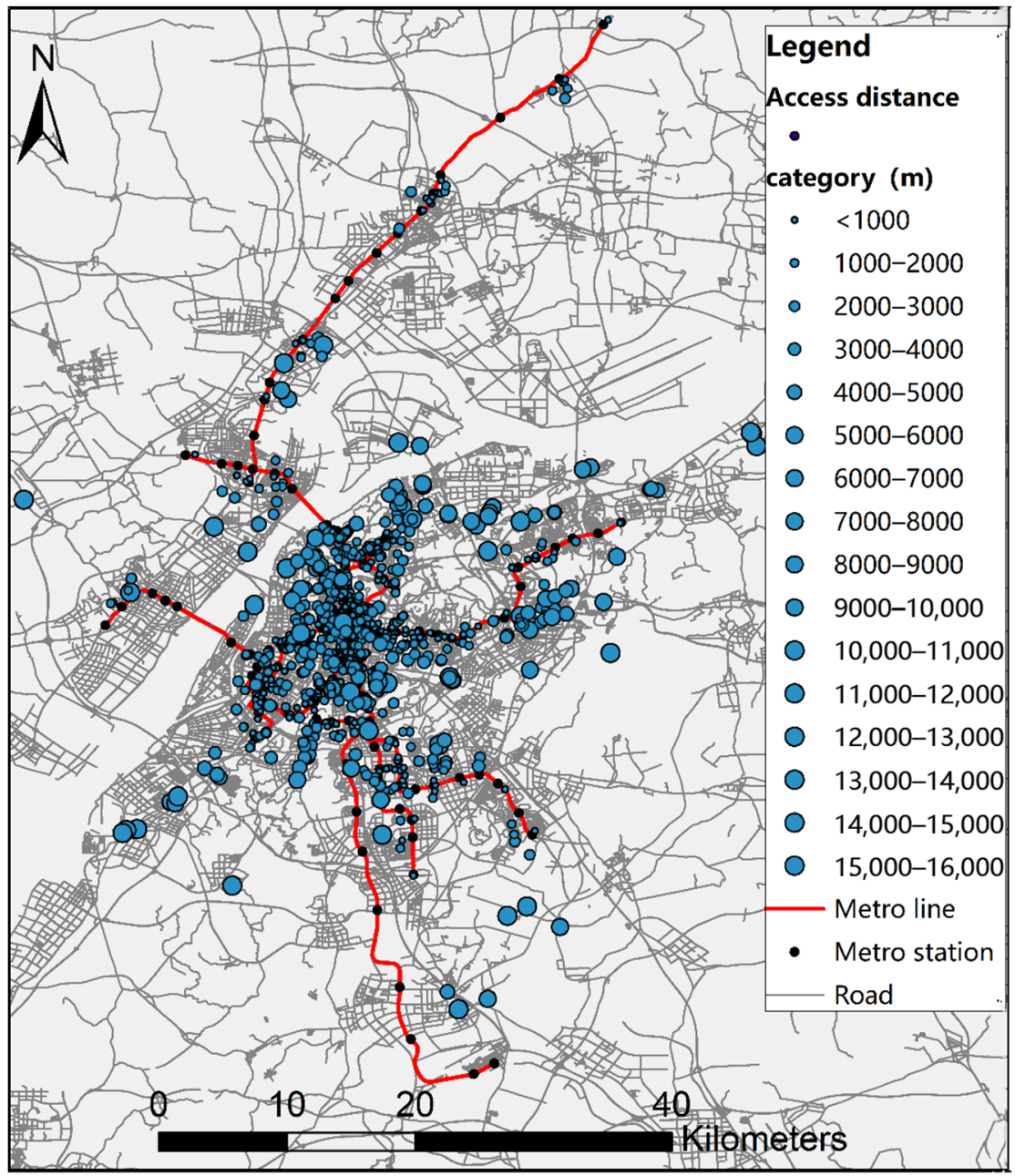

Figure 6. Spatial distribution of access distance.

\subsection{Catchment Area of Metro Station}

Instead of using a circular buffer to delineate the catchment areas, we adopt an approach based on street network to estimate the accessible areas of metro stations by multiple feeding modes [4]. As shown in Figure 7, the service areas of different feeding modes are marked by different colors, and the determination of boundaries of areas for each mode is up to the 85th percentile of access distance. Generally, longer access distance means larger catchment area, but the presented result is also affected by the condition of street network. In the following picture, the part drawn with the deepest color represents the catchment areas of metro-walking pattern, that is to say, most people could walk to access or egress stations willingly within this range. Docked bike-sharing and private bikes are relatively close in distance, thus the difference in service area is less obvious. The catchment area of bus almost overlaps that provided by car, which might indicate that bus-metro integration competes with car-metro integration for long-distance trips.

Meanwhile, it is notable that the catchment areas of metro stations vary between the downtown and suburban areas owing to different densities of street networks. Therefore, two typical stations, Xinjiekou station in downtown, and Mozhoudonglu station in suburban areas, are picked, and their catchment areas are calculated by both a networkbased method and circular method, then compared. As Figure 8 shows, the service area of Mozhoudonglu station for all feeding modes is smaller than that of Xinjiekou station, revealing that the lower density of network leads to narrower areas accessible for travelers. Moreover, the network-based service area of Xinjiekou station almost overlaps its circular 
buffer. By contrast, the circular buffer, without considering the conditions of street network, seems to overestimate the catchment area of Mozhoudonglu station.

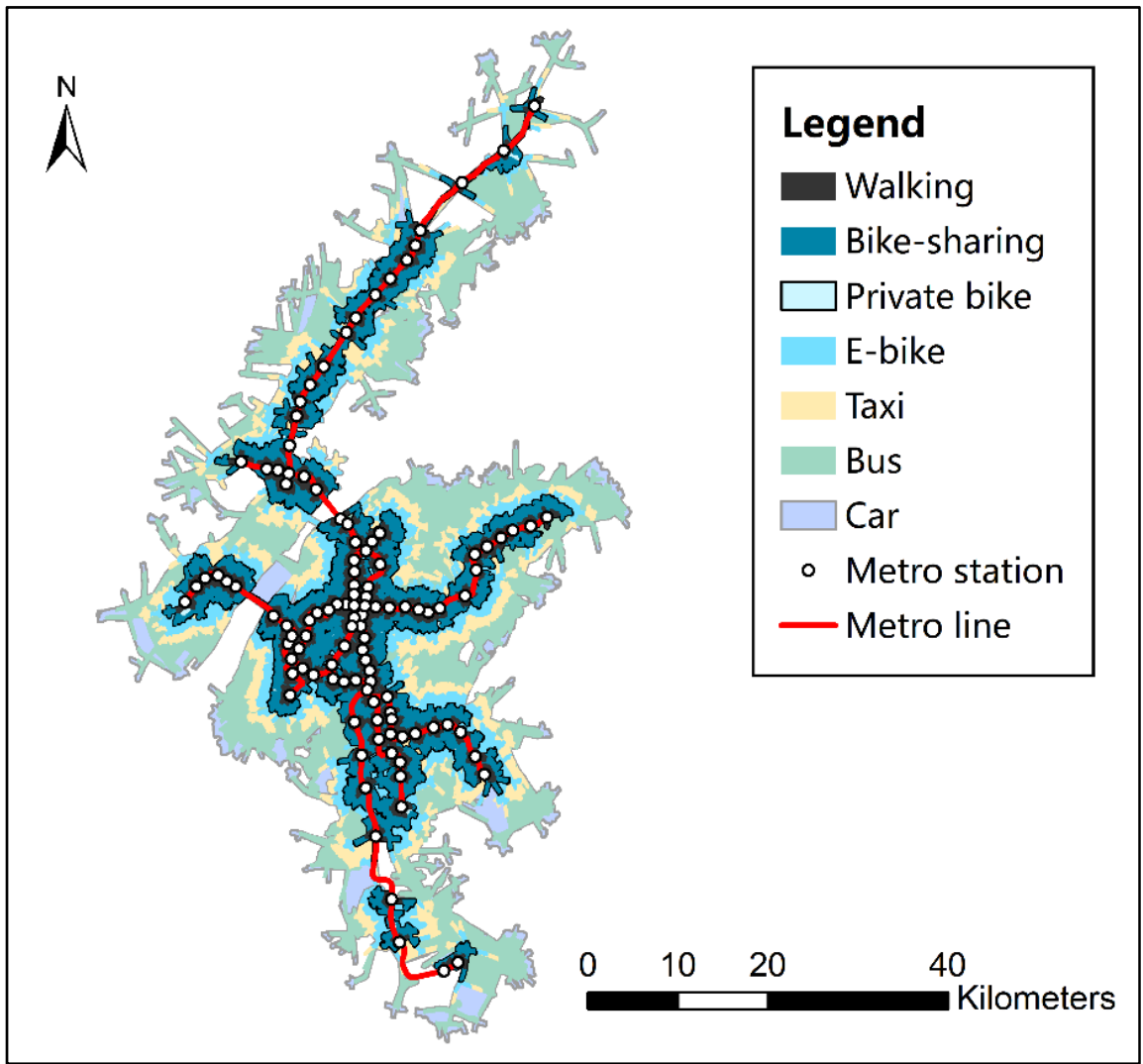

Figure 7. Catchment area delineation.

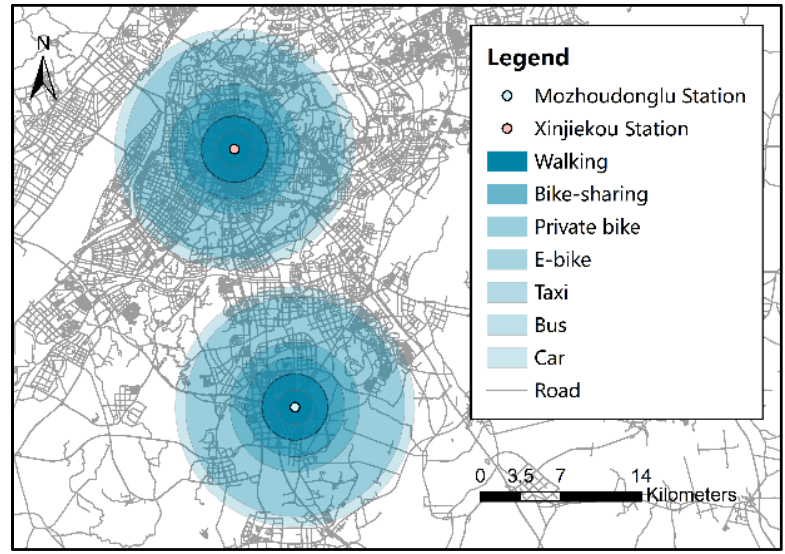

(a) Circular buffer.

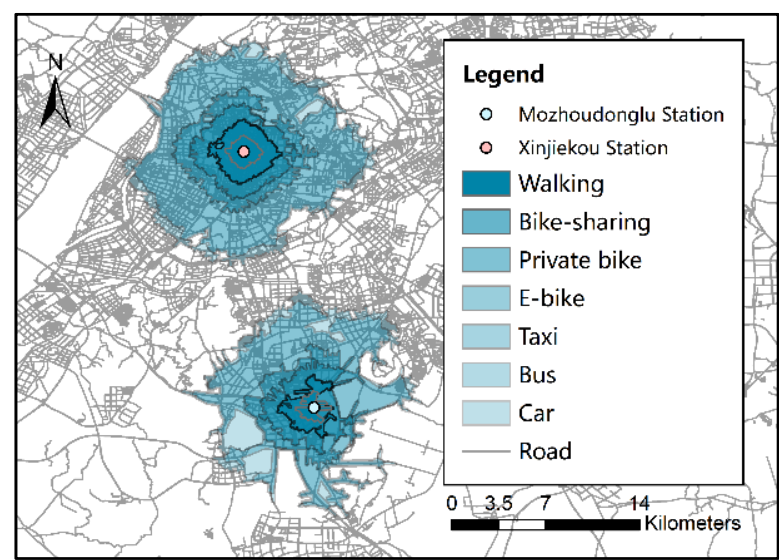

(b) Network-based buffer.

Figure 8. Comparing catchment areas of stations in suburb and downtown.

\section{Conclusions}

It is impossible for people to make door-to-door trips by metro without any transfers. The combination of multiple feeding modes and metro ensures better travel accessibility. For those in charge of city planning and management, it is essential to figure out the characteristics of different feeding modes with respect to access/egress distances and catchment areas of metro stations. This paper uses travel data and GIS data to calculate the network-based distance in both access and egress phases and portrays the catchment 
areas of metro stations for different modes including walking, bus, private bike, docked bike-sharing, private e-bike, taxi, and car.

Findings are as follows:

With regard to transfer mode shares, the distribution of access phase is almost in accordance with that of egress phase. Walking is the most used feeding mode, sharing at nearly $70 \%$ of all transfer trips. Possibly affected by the weather, docked bike-sharing is not as prominent as expected, but is also competitive compared with private bike. To determine the 85th percentile value of access/egress distance, quadratic models and cubic models are applied for multiple feeding modes. Mostly, the average egress distances of these feeding modes are slightly longer than their average access distances. Walking has the shortest feeding distance while docked bike-sharing supports the shortest time cost in both access and egress phase, about $8 \mathrm{~min}$. Private e-bike has superiority over the conventional bike for a longer distance within nearly the same time consumption. Car requires less time to achieve longer access and egress distance than bus. In addition, the spatial characteristics of distribution of access distance demonstrates that the long-distance access trips are very worthy of attention for improvement. As for catchment area delineation, the key factor is the 85th percentile of access distance. A bigger threshold means larger accessible areas of metro stations generally. Circular buffer better suits the determination of service area of metro stations in downtown than that in suburbs.

To summarize, this paper compares both access distance and egress distance and catchment area for multiple feeding modes of metro stations based on a network method. This study has several limitations. First, some emerging transport modes are not involved, such as dockless bike-sharing, electric bike-sharing, and scooters, which provides somewhat of an incomplete picture of multiple feeding modes for metro transferring. Second, the value of access/egress distance and catchment area of multiple feeding modes may vary according to different weather and season. Deeper comparative analysis can be conducted if the survey data can be collected over a longer period. Third, this paper only uses Nanjing as a case study. It may also be useful to obtain the survey data from other cities to examine the multiple feeding modes patterns in other contexts, which could provide some comparisons. In addition, this work could be extended by dividing road networks into different types (e.g., footpath, underground passages, and overpasses) on the basis of different feeding modes. Moreover, it would be interesting to explore the competing, complementing, and extending relationships between multimodal connections and metro by examining the spatial relationship of multimodal connections' origins/destinations and the locations of metro stations. Finally, future studies need to explore how different weather condition, socio-economic, land use, urban density features, and housing buildings influence the access/egress distance and catchment area of multiple feeding modes for metro.

Author Contributions: The authors confirm their contributions to this paper as follows: X.L.: Conceptualization, Methodology; X.M.: Conceptualization, Data curation, Writing-Original draft preparation, Writing-Reviewing and Editing; Z.L.: Data curation, Investigation. All authors checked the results and finalized the manuscript. All authors have read and agreed to the published version of the manuscript.

Funding: This research was funded by National Natural Science Foundation of China, grant number 51908187 and 52172304, and the APC was funded by National Natural Science Foundation of China, grant number 51908187.

Institutional Review Board Statement: Not applicable.

Informed Consent Statement: Not applicable.

Data Availability Statement: Not applicable.

Conflicts of Interest: The authors declare no conflict of interest. 


\section{References}

1. Zuo, T.; Wei, H.; Rohne, A. Determining transit service coverage by non-motorized accessibility to transit: Case study of applying GPS data in Cincinnati metropolitan area. J. Transp. Geogr. 2018, 67, 1-11. [CrossRef]

2. Givoni, M.; Rietveld, P. The access journey to the railway station and its role in passengers' satisfaction with rail travel. Transp. Policy 2007, 14, 357-365. [CrossRef]

3. Wang, J.; Cao, X. Exploring built environment correlates of walking distance of transit egress in the Twin Cities. J. Transp. Geogr. 2017, 64, 132-138. [CrossRef]

4. Wang, Z.-J.; Chen, F.; Xu, T.-K. Interchange between Metro and Other Modes: Access Distance and Catchment Area. J. Urban Plan. Dev. 2016, 142, 04016012. [CrossRef]

5. Weiss, A.; Habib, K.N. Examining the difference between park and ride and kiss and ride station choices using a spatially weighted error correlation (SWEC) discrete choice model. J. Transp. Geogr. 2017, 59, 111-119. [CrossRef]

6. Hsiao, S.; Lu, J.; Sterling, J.; Weatherford, M. Use of Geographic Information System for Analysis of Transit Pedestrian Access. Transp. Res. Rec. 1997, 1604, 50-59. [CrossRef]

7. Zhao, J.; Deng, W.; Song, Y.; Zhu, Y. Analysis of Metro ridership at station level and station-to-station level in Nanjing: An approach based on direct demand models. Transportation 2014, 41, 133-155. [CrossRef]

8. Jun, M.-J.; Choi, K.; Jeong, J.-E.; Kwon, K.-H.; Kim, H.-J. Land use characteristics of subway catchment areas and their influence on subway ridership in Seoul. J. Transp. Geogr. 2015, 48, 30-40. [CrossRef]

9. Wang, Y.; Correia, G.; de Romph, E.; Timmermans, H. Using metro smart card data to model location choice of after-work activities: An application to Shanghai. J. Transp. Geogr. 2017, 63, 40-47. [CrossRef]

10. Kuby, M.; Barranda, A.; Upchurch, C. Factors influencing light-rail station boardings in the United States. Transp. Res. Part A Policy Pract. 2004, 38, 223-247. [CrossRef]

11. Cardozo, O.D.; García-Palomares, J.C.; Gutiérrez, J. Application of geographically weighted regression to the direct forecasting of transit ridership at station-level. Appl. Geogr. 2012, 34, 548-558. [CrossRef]

12. Rastogi, R.; Rao, K.V.K. Travel Characteristics of Commuters Accessing Transit: Case Study. J. Transp. Eng. 2003, 129, 684-694. [CrossRef]

13. Zhao, J.; Deng, W. Relationship of Walk Access Distance to Rapid Rail Transit Stations with Personal Characteristics and Station Context. J. Urban Plan. Dev. 2013, 139, 311-321. [CrossRef]

14. Ji, Y.; Fan, Y.; Ermagun, A.; Cao, X.; Wang, W.; Das, K. Public bicycle as a feeder mode to rail transit in China: The role of gender, age, income, trip purpose, and bicycle theft experience. Int. J. Sustain. Transp. 2017, 11, 308-317. [CrossRef]

15. Li, Z.; Wang, W.; Yang, C.; Ding, H. Bicycle mode share in China: A city-level analysis of long term trends. Transportation 2017, 44, 773-788. [CrossRef]

16. Taylor, D.; Mahmassani, H. Analysis of stated preferences for intermodal bicycle-transit interfaces. Transp. Res. Rec. 1996, 1556, 86-95. [CrossRef]

17. Hochmair, H.H. Assessment of Bicycle Service Areas around Transit Stations. Int. J. Sustain. Transp. 2015, 9, 15-29. [CrossRef]

18. Lee, J.; Choi, K.; Leem, Y. Bicycle-based transit-oriented development as an alternative to overcome the criticisms of the conventional transit-oriented development. Int. J. Sustain. Transp. 2016, 10, 975-984. [CrossRef]

19. Cheng, Y.-H.; Lin, Y.-C. Expanding the effect of metro station service coverage by incorporating a public bicycle sharing system. Int. J. Sustain. Transp. 2018, 12, 241-252. [CrossRef]

20. Ma, T.; Liu, C.; Erdoğan, S. Bicycle Sharing and Public Transit Does Capital Bikeshare Affect Metrorail Ridership in Washington, DC? Transp. Res. Rec. 2015, 2534, 1-9. [CrossRef]

21. Fyhri, A.; Fearnley, N. Effects of e-bikes on bicycle use and mode share. Transp. Res. Part D Transp. Environ. 2015, 36, 45-52. [CrossRef]

22. Fyhri, A.; Heinen, E.; Fearnley, N.; Sundfør, H.B. A push to cycling exploring the e-bike's role in overcoming barriers to bicycle use with a survey and an intervention study. Int. J. Sustain. Transp. 2017, 11, 681-695. [CrossRef]

23. Plazier, P.A.; Weitkamp, G.; Berg, A.E.V.D. “Cycling was never so easy!” An analysis of e-bike commuters' motives, travel behaviour and experiences using GPS-tracking and interviews. J. Transp. Geogr. 2017, 65, 25-34. [CrossRef]

24. Talamini, G.; Ferreira, D.P. An informal transportation as a feeder of the rapid transit system. Spatial analysis of the e-bike taxi service in Shenzhen, China. Transp. Res. Interdiscip. Perspect. 2019, 1, 100002. [CrossRef]

25. Lin, D.; Zhang, Y.; Zhu, R.; Meng, L. The analysis of catchment areas of metro stations using trajectory data generated by dockless shared bikes. Sustain. Cities Soc. 2019, 49, 101598. [CrossRef]

26. Guo, Y.; Yang, L.; Lu, Y.; Zhao, R. Dockless bike-sharing as a feeder mode of metro commute? The role of the feeder-related built environment: Analytical framework and empirical evidence. Sustain. Cities Soc. 2021, 65, 102594. [CrossRef]

27. Pan, H.; Shen, Q.; Xue, S. Intermodal Transfer between Bicycles and Rail Transit in Shanghai, China. Transp. Res. Rec. J. Transp. Res. Board 2010, 2144, 181-188. [CrossRef]

28. Wang, Z.-J.; Liu, Y.; Chen, F. Evaluation and Improvement of the Interchange from Bus to Metro Using Smart Card Data and GIS. J. Urban Plan. Dev. 2018, 144, 05018004. [CrossRef]

29. Santoso, D.S.; Sakamoto, K.; Yajima, M.; Kubotoa, H. Trip Characteristics of Commuters Accessing Rail Transit by Considering Distance and Slope with Integration of Public Bus as a Feeder. J. East. Asia Soc. Transp. Stud. 2015, 11, $1479-1494$. 
30. Yang, M.; Zhao, J.; Wang, W.; Liu, Z.; Li, Z. Metro commuters' satisfaction in multi-type access and egress transferring groups. Transp. Res. Part D Transp. Environ. 2015, 34, 179-194. [CrossRef]

31. Buehler, R. Can Public Transportation Compete with Automated and Connected Cars? J. Public Transp. 2018, 21, 7-18. [CrossRef]

32. Wang, F.; Ross, C.L. New potential for multimodal connection: Exploring the relationship between taxi and transit in New York City (NYC). Transportation 2017, 46, 1051-1072. [CrossRef]

33. Li, M.; Dong, L.; Shen, Z.; Lang, W.; Ye, X. Examining the Interaction of Taxi and Subway Ridership for Sustainable Urbanization. Sustainability 2017, 9, 242. [CrossRef]

34. Jiang, S.; Guan, W.; He, Z.; Yang, L. Exploring the Intermodal Relationship between Taxi and Subway in Beijing, China. J. Adv. Transp. 2018, 2018, 1-14. [CrossRef]

35. The Population of Nanjing. 2018. Available online: http://www.chamiji.com/201806046098.html (accessed on 16 August 2018)

36. Nanjing Metro. 2021. Available online: https://baike.baidu.com/item/\%E5\%8D $\% 97 \% E 4 \% B A \% A C \% E 5 \% 9 C \% B 0 \% E 9 \% 93 \% 81 / 5$ 045076?fr=aladdin (accessed on 15 January 2022).

37. Efforts of Nanjing Transportation Bureau in the Past Five Years. 2017. Available online: http://jiangsu.sina.com.cn/news/2017-0 7-22/detail-ifyihrit1200076.shtml (accessed on 11 July 2017).

38. Hino, S.; Kishi, K.; Sato, K. Development of the Complementary Accessibility Index and Evaluation of Public Transportation System. J. City Plan. Inst. Jpn. 2000, 35, 475-480. [CrossRef]

39. El-Geneidy, A.; Grimsrud, M.; Wasfi, R.; Tétreault, P.; Surprenant-Legault, J. New evidence on walking distances to transit stops: Identifying redundancies and gaps using variable service areas. Transportation 2014, 41, 193-210. [CrossRef]

40. Parkin, J.; Wardman, M.; Page, M. Estimation of the determinants of bicycle mode share for the journey to work using census data. Transportation 2008, 35, 93-109. [CrossRef]

41. Ma, X.; Ji, Y.; Yang, M.; Jin, Y.; Tan, X. Understanding bikeshare mode as a feeder to metro by isolating metro-bikeshare transfers from smart card data. Transp. Policy 2018, 71, 57-69. [CrossRef]

42. Fishman, E.; Cherry, C. E-bikes in the Mainstream: Reviewing a Decade of Research. Transp. Rev. 2016, 36, 72-91. [CrossRef]

43. He, S.Y.; Giuliano, G. Factors affecting children's journeys to school: A joint escort-mode choice model. Transportation 2017, 44, 199-224. [CrossRef]

44. Olszewski, P.; Wibowo, S.S. Using equivalent walking distance to assess pedestrian accessibility to transit stations in Singapore, Transit: Planning, Management and Maintenance, Technology, Marketing and Fare Policy, and Capacity and Qualtiy of Sevice. Transp. Res. Rec. 2005, 1927, 38-45. [CrossRef]

45. Vuchic, V.R.; Kikuchi, S. Design of outlying rapid transit station areas. Transp. Res. Rec. 1974, 505, 1-12.

46. Tirachini, A. The economics and engineering of bus stops: Spacing, design and congestion. Transp. Res. Part A Policy Pract. 2014, 59, 37-57. [CrossRef]

47. Yang, M.; Wu, J.X.; Zhao, J.Y.; You, Y.T.; Zhang, M.K.; Sun, S.Y. Optimizing Multimodal Transfer Facility Design for Urban Rail Transit Service. Urban Transp. China 2017, 15, 64-69. 